\title{
Comparison of Whole Plant and Detached Leaf Screening Techniques for Identifying Anthracnose Resistance in Strawberry Plants
}

Melinda A. Miller-Butler, ${ }^{\dagger}$ Barbara J. Smith, and Ebrahiem M. Babiker, U.S. Department of Agriculture, Agricultural Research Service, Poplarville, MS 39470; Brian R. Kreiser, Department of Biological Sciences, University of Southern Mississippi, Hattiesburg, MS 39406; and Eugene K. Blythe, Coastal Research and Extension Center, Mississippi State University, South Mississippi Branch Experiment Station, Poplarville, MS 39470

\begin{abstract}
Anthracnose is a destructive disease of strawberry caused by several Colletotrichum species including C. acutatum, C. fragariae, and C. gloeosporioides. Identification of anthracnose resistant strawberry germplasm has commonly relied on inoculation of whole plants with isolates of these pathogens. In this study, whole plants and detached leaves from 81 germplasm lines were inoculated with a conidial suspension of isolates of $C$. acutatum, $C$. fragariae, and $C$. gloeosporioides, incubated in the dark at $30^{\circ} \mathrm{C}, 100 \%$ relative humidity, for $48 \mathrm{~h}$, and assessed for disease severity based on symptoms on inoculated petioles and leaves. The correlation between the disease severity ratings of the whole plants rated 30 days after inoculation and detached leaves rated 5 days after

inoculation was determined. Based on leaf symptoms and petiole lesions, the association between the whole plant leaf disease severity rating (DSR) and detached leaf DSR was positive $\left(r_{p}=0.70\right)$, and the association between the whole plant DSR and the detached leaf DSR was also positive $\left(r_{p}=0.66\right)$. Whole plant and detached leaf DSRs were used to assign each germplasm line to a resistance category, and a posthoc Tukey's test showed that the whole plant DSR means and the detached leaf DSR means for each resistance category differed significantly at $p<0.05$. This research was used to develop a strawberry detached leaf assay which can reliably and quickly determine the degree of resistance of strawberry germplasm to anthracnose.
\end{abstract}

The strawberry (Fragaria $\times$ ananassa Duch.) is a popular fruit grown in most arable regions of the world; however, it is also host to many pathogens that cause major losses in strawberry production. Anthracnose is a destructive disease of strawberry caused by several Colletotrichum species including C. acutatum J. H. Simmonds, C. fragariae A. N. Brooks, and C. gloeosporioides (Penz.) Penz. \& Sacc. (teleomorph: Glomerella cingulata (Stoneman) Spauld. \& H. Schrenk) (Howard et al. 1992; Smith 2008). C. acutatum, first reported on strawberry in the United States by Smith and Black (1986), primarily causes anthracnose fruit rot, but may cause anthracnose disease on the runners, petioles, leaves, and roots (Howard et al. 1992; Smith 1998c). C. acutatum was treated as a morphological variant of C. gloeosporioides until Simmonds (1965) described it as a distinct species. Recently, molecular testing has shown $C$. acutatum to be a species complex of 31 morphologically similar species. Strawberry isolates, included in their study, were found to be in the C. nymphaeae clade (Damm et al. 2012). Both C. fragariae and C. gloeosporioides can infect all aboveground parts of the plant and cause anthracnose fruit rot, anthracnose crown rot, and anthracnose leaf spot (Smith 1998a, b). C. gloeosporioides exhibits a wide variation in morphology on different host plant species and is composed

Current address of M. A. Miller-Butler: Jones County Junior College, 102B Harris Science Building, 900 S. Court Street, Ellisville, M.S. 39437

${ }^{\dagger}$ Corresponding author: M. A. Miller-Butler;

E-mail: Melinda.Butler@jcjc.edu

Funding: This research was supported in part by grants from the North American Strawberry Growers Association (NASGA).

The use of trade, firm, or corporation names in this publication is for the information and convenience of the reader. Such use does not constitute an official endorsement or approval by the United States Department of Agriculture or the Agricultural Research Service of any product or service to the exclusion of others that may be suitable.

Accepted for publication 8 April 2018.

This article is in the public domain and not copyrightable. It may be freely reprinted with customary crediting of the source. The American Phytopathological Society, 2018. of a complex of morphologically similar species. $C$. fragariae is included in the $C$. gloeosporioides complex. Molecular characterization found that isolates of $C$. fragariae were synonymous with isolates of $C$. theobromicola, an earlier name for $C$. fragariae (Weir et al. 2012); and C. gloeosporioides isolates were also genetically related to $C$. fructicola and $C$. siamense.

Transplant materials with quiescent infections are often the initial source of Colletotrichum inoculum in strawberry production fields (Rahman and Louws 2008). Cultural practices and fungicides are commonly used to control anthracnose diseases, but frequent use of the same fungicides has led to the development of fungicideresistant Colletotrichum strains (Forcelini et al. 2016; Smith et al. 2013). A most desirable means for controlling anthracnose is through the use of resistant strawberry cultivars (Agrios 2005; Poling 2008). Cultivars resistant to $C$. fragariae have been found to decrease the rate of disease spread in fields (Delp and Milholland 1980, 1981); however, anthracnose-resistant cultivars with desirable horticultural qualities adapted to various regions are needed. Planting resistant cultivars will reduce economic losses caused by anthracnose, reduce the use of fungicides, and reduce the chances of spreading Colletotrichum in nursery stock.

After a severe anthracnose epidemic in the 1970s, the USDAAgricultural Research Service (ARS) established a strawberry breeding program in Poplarville, MS (Smith 2006). The goal was to develop strawberry germplasm resistant to anthracnose crown rot, caused by $C$. fragariae, and adapted to the southeastern United States. A whole plant inoculation protocol for identifying strawberry germplasm with resistance to $C$. fragariae was developed (Smith and Black 1987; Smith and Spiers 1982) whereby greenhouse-grown plants to be screened for resistance were inoculated with a conidial suspension of $C$. fragariae isolates and assessed for anthracnose symptoms. Anthracnose-resistant selections were chosen based on field testing of these resistant plants for horticultural traits and given the prefix MSUS to denote that they originated from the USDA breeding program in Mississippi. One of these MSUS clones was released as the anthracnose-resistant cultivar Pelican (Smith et al. 1998), and four others were released as the breeding lines US70, US159, US292, and US438 (Galletta et al. 1993).

Successful disease screening of large plant populations requires that the disease response be assessed with accurate and reproducible techniques. Although whole plant inoculation assays to screen for 
anthracnose resistance have been demonstrated to be accurate and reproducible (Chang and Smith 2007; Lewers et al. 2007; Osorio et al. 2014; Smith 2008), they are time-consuming, and plants are often killed by the disease, which can present a problem for the breeder because the germplasm may have possessed other desirable horticultural traits. Screening for anthracnose resistance using detached strawberry leaves is an alternative to inoculating whole plants and can possibly eliminate the destruction of desirable germplasm. Detached leaf inoculation assays are being used to determine plant germplasm resistance to disease, such as for tomato, Solanum lycopersicum L., germplasm resistant to late blight (Foolad et al. 2015), apple genotypes being tested for resistance to Alternaria blotch (Abe et al. 2010), and American chestnut, Castanea dentata, germplasm resistant to chestnut blight (Newhouse et al. 2014). Research on the development of a detached strawberry leaf inoculation protocol has been ongoing at the USDA-ARS in Poplarville, MS (MillerButler et al. 2013). Our goal was to develop a reliable anthracnose screening protocol using a detached leaf that would reduce the time between inoculation and disease assessment. Our approach was to inoculate detached leaves and assess symptom development using a disease severity rating (DL-DSR) and then assess the validity of this assay by comparison with disease severity ratings of inoculated whole plants (WP-DSR) and disease severity ratings of the leaf with the greatest disease symptoms still attached to each inoculated whole plant (L-DSR). This detached leaf assay should reduce the overall time needed for breeders to identify anthracnose resistant germplasm. It would also preserve valuable germplasm since plants of susceptible breeding lines would not be killed, and it allows for evaluation using isolates of the pathogens from other areas without the risk of those isolates infecting nearby plants.

\section{Materials and Methods}

Plant materials. Strawberry cultivars were either purchased from commercial strawberry nurseries or obtained as in vitro plantlets from the USDA-ARS Germplasm Repository, Corvallis, OR. Thirty-one cultivars [including cultivars with known anthracnose reactions: Elsanta, susceptible to C. acutatum (Denoyes and Baudry 1995; Denoyes-Rothan and Guérin 1996), Chandler, susceptible to C. fragariae and C. gloeosporioides (Chang and Smith 2007), and Pelican, resistant to $C$. fragariae and C. gloeosporioides (Osorio et al. 2014; Smith et al. 1998)] and 50 MSUS clones (including US70, US159, and US292, resistant to $C$. fragariae and $C$. gloeosporioides) were established in 10-cm plastic pots in a 1:1 mixture of Jiffy-Mix (Jiffy Products of America Inc., West Chicago, IL) and sand. Plants used in the study were propagated by rooting young runner plants in the Jiffy-Mix:sand potting mixture and maintained in a greenhouse at $28^{\circ} \mathrm{C} \pm 10^{\circ} \mathrm{C}$ with a 16 -h photoperiod, and fertilized every 16 weeks with 0.6 grams/pot of Osmocote (ICL Specialty Fertilizers - North America, Dublin, OH)14-14-14 time-released fertilizer. Plants were established at the beginning of the study and used in all three seasons for both the whole plant and detached leaf inoculations. Plants used for inoculations were not reintroduced to the study but were kept in a separate greenhouse. Cultivars and MSUS clones of strawberries used in this study were collectively referred to as germplasm lines.

Colletotrichum isolates. Five Colletotrichum isolates were used: two isolates of $C$. acutatum, Goff and Ca-1; two isolates of $C$. fragariae, Cf-63 and Cf-75; and one isolate of C. gloeosporioides, Cg-162 (Chang and Smith 2007; Smith and Black 1990). Each isolate was initiated from silica gel cultures and grown on a 1:1 mixture of oatmeal and potato dextrose agars at $20-28^{\circ} \mathrm{C}$ under fluorescent lights with a 12-h photoperiod.

Morphological characterization. Colony color and conidial shape and size were evaluated for each isolate after 10 days growth on potato dextrose agar at $25^{\circ} \mathrm{C}$ under continuous fluorescent lighting. Conidia were harvested, suspended in sterile deionized water, placed on microscope slides with $0.4 \%$ trypan blue stain, magnified $\times 400$, and photographed with an Olympus DP72 camera (Olympus, Center Valley, PA), using Olympus DP2-BSW software. The photographs were increased $200 \%$, and 50 randomly chosen conidia were measured for length and width (Smith and Black 1990).
Molecular characterization. Genomic DNA was extracted from the five isolates following a protocol described by Babiker et al. (2012). The ITS1 and ITS4 primer pairs (White et al. 1990) were used to amplify the internal transcribed spacer (ITS)1, ITS2, and $5.8 \mathrm{~s}$ regions of ribosomal DNA (rDNA). Partial sequences of the glyceraldehyde-3-phosphate dehydrogenase (GAPDH) and beta tubulin 2 (TUB2) genes were amplified using GDF1 and GDR2 (Templeton et al. 1992), and T1 and T2 primer pairs (O'Donnell and Cigelnik 1997), respectively. These genes were amplified in $20-\mu 1$ volumes via the polymerase chain reaction (PCR) using conditions described by Weir et al. (2012). The PCR products were separated in $2 \%$ agarose gel, and the desired fragments were purified using QIA quick gel extraction kit and following the manufacture's protocol (Qiagen, Inc., German Town, MD). The purified PCR products were sequenced in both directions by Elim Biopharmaceutical Inc. (Hayward, CA). Comparison of the sequences with sequences in the GenBank database (https://blast.ncbi.nlm.nih.gov/Blast.cgi) was performed using the Basic Local Alignment Search Tool (BLAST; Altschul et al. 1997).

Preparation of inoculum. Inoculum was prepared as a conidial suspension obtained from 7- to 14-day-old cultures by flooding each culture plate with sterile deionized water and gently scraping the agar surface with a glass rod to remove conidia. The resulting conidial suspension was filtered through one layer of bandage gauze (Johnson and Johnson, New Brunswick, NJ) and adjusted to a concentration of $1.5 \times 10^{6}$ conidia/ml by diluting with sterile deionized water with Tween 20 (Sigma Chemical Co., St. Louis, MO) added as a surfactant at the rate of one drop per 1 liter of deionized water.

Whole plant inoculations. Whole plant inoculations were conducted three times over 2 years (summer and winter 2010, and summer 2011), which will hereafter be referred to as three "seasons." Four replicates of each germplasm line consisting of one plant per repetition were inoculated in each season with each of the Colletotrichum isolates. Whole strawberry plants of 31 cultivars and 50 MSUS clones were inoculated with two isolates of $C$. acutatum (Goff and $\mathrm{Ca}-1$ ), two isolates of $C$. fragariae (Cf-63 and Cf-75), and one isolate of $C$. gloeosporioides (Cg-162), using one isolate for inoculum at a time. A total of 3,754 observations were made: 3,230 inoculated plants and 524 noninoculated controls. However, not all genotype $\times$ isolate combinations were used in each season due to the small starting population of many of the MSUS clones. Older leaves, runners, and flowers were removed from plants 3 to 4 days before inoculation, leaving 4 to 5 young leaves on each plant at inoculation. Plants were inoculated with $\left(1.5 \times 10^{6}\right.$ conidia $\left./ \mathrm{ml}\right)$ conidial suspension by misting to the point of runoff using a hand pump sprayer, and plants used for noninoculated controls were misted with deionized water. Plants were immediately placed in a dew chamber at $100 \%$ $\mathrm{RH}, 30^{\circ} \mathrm{C}$, incubated in the dark for $48 \mathrm{~h}$, and then transferred to a greenhouse bench in randomized complete blocks, except for the noninoculated control plants which were placed on the same bench in a randomized block away from the inoculated plants to prevent cross contamination. The plants were maintained in the greenhouse at $28^{\circ} \mathrm{C} \pm 10^{\circ} \mathrm{C}$ ) for the remainder of the study (Smith and Black 1987). Disease development was assessed by two independent raters at 30 days after inoculation (DAI) using a disease severity rating (DSR) scale adapted from Smith and Black (1987). Whole plant ratings were based on petiole lesions: $0=$ healthy plant with no visible lesions, $1=<3 \mathrm{~mm}$ long petiole lesion, $2=3$ to $10 \mathrm{~mm}$ long petiole lesion, $3=>10-20 \mathrm{~mm}$ long petiole lesion, $4=>20 \mathrm{~mm}$ long petiole lesion, $5=$ youngest leaf wilted, and $6=$ plant dead. Plants with a DSR $\leq 2.0$ were considered resistant, those with a DSR $>2.0$ to $<4.0$ were considered intermediate, and those with a DSR $\geq 4.0$ were considered susceptible.

When a whole plant DSR was assessed, the leaf (composed of three leaflets on a petiole) with the greatest disease symptoms was simultaneously rated for disease severity. This rating was used to classify the anthracnose response of a leaf from the whole plant and correlate it with both the whole plant DSR and the detached leaf DSR. The DSR scale used to evaluate the leaf was: $0=$ no visible 
disease symptom on any leaflet, 1 through $4=$ increasing disease symptom severity, and $5=$ total area of leaflets necrotic.

Detached leaf inoculations. The detached leaf inoculations were conducted three times over 3 years (fall 2009, spring 2010, spring 2011). Four replicates of each germplasm line consisting of one detached leaf were inoculated each year. Young, fully developed, blemish-free leaves, composed of three leaflets on a petiole, and at an equivalent developmental stage as those evaluated in the whole plant leaf assay were removed from the same set of plants used in the whole plant assay. No more than one leaf per whole plant was removed for each inoculation. The petiole was inserted into a $10 \times$ $150 \mathrm{~mm}$ test tube filled with sterile deionized water. Detached leaves were inoculated with conidial suspension $\left(1.5 \times 10^{6}\right.$ conidia $\left./ \mathrm{ml}\right)$ by misting the adaxial surface of the leaflets to the point of runoff using a hand pump sprayer. Detached leaves used for noninoculated controls were misted with deionized water. Test tubes containing the inoculated leaves were placed in a completely random design into test tube racks with six test tubes per rack, then the racks were placed inside a dew chamber in a completely random design, and incubated at $100 \% \mathrm{RH}, 30^{\circ} \mathrm{C}$, in the dark for $48 \mathrm{~h}$. Noninoculated leaves were placed in a random design in separate racks and placed on a different shelf in the dew chamber from the inoculated leaves. To maintain the turgidity of the leaves during incubation, they were removed from the dew chamber and transferred to sealed, clear plastic containers, three racks per container in a random design, and held at $100 \% \mathrm{RH}$ and $23-25^{\circ} \mathrm{C}$ with continuous fluorescent light for an additional 3 days before assessing disease symptoms. The inoculated and the noninoculated control detached leaves were assessed for disease severity using the same scale described above for the leaf in the whole plant inoculations.

Hereafter, the whole plant DSR will be referred to as WP-DSR, the leaf DSR from the whole plant inoculations will be referred to as L-DSR, and the detached leaf DSR will be referred to as DL-DSR. C. acutatum isolates Goff and Ca-1 were initially included in these studies, but no disease symptoms developed on leaves in the detached leaf study; therefore, these isolates were removed from the detached leaf inoculations and from the comparisons of the disease severity ratings with the whole plants.

Experimental design and statistical analysis. Plants and/or leaves were chosen randomly from the population of that germplasm line to either be inoculated or to serve as a noninoculated control. The WP-DSR for each of the individual plants within a germplasm line from each of the three inoculation seasons was used to calculate the mean WP-DSR for that germplasm line. The L-DSR for each of the germplasm lines from each of the three whole plant inoculation studies was used to calculate the mean L-DSR for each germplasm line. The detached leaf inoculations were conducted three times over 3 years, and the DL-DSR for each of the individual leaves within a germplasm line from each of the three inoculation studies was used to calculate the mean DL-DSR for the germplasm line. The noninoculated controls in the whole plant experiments had an overall WP-DSR mean of 0.31 and an overall L-DSR mean of 0.35 , and the noninoculated controls from the detached leaf experiments had an overall DL-DSR mean of 0.09. This indicates that neither the whole plants nor detached leaves used for the inoculation studies were infected with Colletotrichum species prior to the studies; therefore, the data from the noninoculated controls were removed from further statistical evaluations.

The mean WP-DSR, L-DSR, and DL-DSR data from the whole plant and detached leaf inoculation assays were analyzed for association using Pearson's correlation coefficient and for interrater agreement with a weighted kappa coefficient. The mean DSR data for the whole plant (WP-DSR and L-DSR) inoculations and the mean DSR data for the detached leaf (DL-DSR) inoculations, based on the categories (resistant, intermediate, or susceptible) were analyzed with analysis of variance (ANOVA). If significant differences were found with ANOVA, a posthoc Tukey's test was performed.

The data were then analyzed with ANOVA for each isolate separately, using germplasm group (cultivar or MSUS clone), season, and germplasm group $\times$ season as independent variables and WP-DSR as the dependent variable; the same analysis was conducted with the L-DSR as the dependent variable. Due to the difference in rating scales (whole plant: 0 to 6 and leaf: 0 to 5), the WP-DSR of any germplasm line with a WP-DSR mean rating $>5.0$ was adjusted to equal 5 (youngest leaf wilted) for analysis of agreement between the whole plant and leaf ratings. This allowed all data from the two DSR scales to be analyzed using the same scale. A WP-DSR of 5 and 6 are comparable to a category of susceptible when determining the resistance of the germplasm. Data were analyzed for association (precision) using the CORR (version 9.4; SAS Institute Inc., Cary, NC) procedure of SAS. The WP-DSR for all plants in each germplasm line was averaged across each fungal species, and the average was used to assign resistance categories $(\mathrm{R}=$ resistant, $\mathrm{I}=$ intermediate, $\mathrm{S}=$ susceptible $)$ to each germplasm line.

\section{Results}

Morphological characterization. Colony color of the C. acutatum isolates was white to light gray covered with orange-colored conidial masses, and the conidia were fusiform in shape. The C. fragariae isolates were beige to dark gray in color covered in salmon-colored conidial masses, and the conidia were cylindrical with one end slightly pointed. The $C$. gloeosporioides isolate was a gray-brown in color, and the conidia were cylindrical but shorter than the $C$. fragariae with both ends rounded. The average length $\times$ width measurements in micrometers $(\mu \mathrm{m})$ for 50 conidia were: $C$. acutatum isolates Ca-1 $11.3 \times 4.4$ and Goff $13.9 \times 5.1 ; C$. fragariae isolates Cf-63 $13.7 \times 5.2$ and Cf-75 $14.8 \times 5.9$; and C. gloeosporioides isolate $\mathrm{Cg}-16214.8 \times 5.9$.

Molecular characterization. The ITS1 and ITS4 primer pairs amplified about 610-bp fragment from each of the five isolates. Comparison of these sequences with the GenBank ITS sequences indicated that the sequences were $97-100 \%$ identical to either $C$. acutatum, C. gloeosporioides, or $C$. fragariae (GenBank accession numbers KX344998.1, KT342872.1, and KC411911.1, respectively), confirming the original morphological classification of each isolate. The T1 and T2 primer pairs amplified about $600 \mathrm{bp}$ to $563 \mathrm{bp}$ from the $\beta$-tubulin gene and were used in BLAST. Sequence analysis of the $\beta$-tubulin amplified from the two $C$. fragariae isolates showed $100 \%$ similarity to $C$. theobromicola isolates (GenBank accession numbers KX721066.1, KX721065.1, KU743292.1, and KU221390.1), further classifying the two isolates originally identified as $C$. fragariae to be $C$. theobromicola. The GDF1 and GDR2 primer pairs amplified about $250 \mathrm{bp}$ from the GAPDH gene. Comparison of 216 to $247 \mathrm{bp}$ with sequences in GenBank revealed $100 \%$ similarity to C. nymphaeae (GenBank accession number KM 252141.1), indicating that the sequence of the isolate originally identified as $C$. acutatum to be $C$. nymphaeae (a member of the C. acutatum complex). Nucleotide alignment of 228 bp amplified from the $C$. gloeosporioides isolate with sequences in GenBank showed $100 \%$ similarity to $C$. fructicola sequence (GenBank accession number JX009914.1), indicating the isolate originally identified as $C$. gloeosporioides to be C. fructicola (a member of the C. gloeosporioides complex). This is in agreement with recent multigene sequence analyses results reported by Munir et al. (2016).

Whole plant and detached leaf disease severity association. The two independent raters' DSRs had a strong, positive correlation and substantial interrater agreement for WP-DSRs $\left(n=3,230, r_{p}=0.89\right.$, $\left.k_{w}=0.89\right)$ and L-DSRs $\left(n=3,230, r_{p}=0.87, k_{w}=0.87\right)($ Gwet 2012), and the interrater agreement was "almost perfect" based on the kappa statistic interpretation by Viera and Garrett (2005). Therefore, the two visual raters' DSRs for each plant were averaged for the remainder of the statistical analyses and will be referred to as the WP-DSRs means and the L-DSRs means.

ANOVA revealed significant germplasm line $\times$ season interactions for the WP-DSR for all isolates (ranging from $P<0.0001$ to $P=0.04)$ and for L-DSR $(P<0.0001)$. The differences in disease development between seasons were considered to be attributable to some germplasm lines that were not inoculated with all Colletotrichum isolates in all three seasons. If there was not enough suitable plant material of a germplasm line available to be inoculated with 
all three isolates, that line was inoculated with isolates CF-75 and CG-162. Therefore, the data were separated to include only those germplasm lines (17 cultivars and 39 MSUS clones) inoculated with isolate Cf-75 and those (23 cultivars and 30 MSUS clones) inoculated with isolate $\mathrm{Cg}-162$ in all three seasons for analysis with ANOVA using germplasm line, season, and germplasm line $\times$ season for each isolate as independent variables and WP-DSRs as the dependent variable, with separate analyses for each isolate.

The germplasm line $\times$ season interaction was significant $(P<$ $0.0001)$ for both isolates Cf-75 $(n=654)$ and Cg-162 $(n=620)$. This was considered to be due to the MSUS clones originally having been selected for resistance to C. fragariae (Galletta et al. 1993; Smith et al. 1998); and the cultivars having not been selected for resistance to $C$. fragariae (with the exception of 'Pelican'), but rather having been selected for many other quality attributes. The data were analyzed for the null hypothesis of no difference in WP-DSRs of cultivars and MSUS clones to inoculation with isolates Cf-75 and Cg-162. ANOVA revealed a significant difference in the WP-DSRs response of cultivars and MSUS clones $(P<0.0001)$; therefore, the null hypothesis was rejected.

The cultivar $\times$ season interaction for WP-DSRs of germplasm inoculated with isolate Cf-75 was significant for cultivars $(P<0.0001)$ and marginally significant for MSUS clones $(P=0.089)$ (Table 1$)$. The cultivar $\times$ season interaction for WP-DSRs of germplasm inoculated with isolate $\mathrm{Cg}-162$ was not significant for cultivars $(P=$ $0.398)$ but was significant for MSUS clones $(P=0.03)$. The cultivar $\times$ season interaction for L-DSRs was marginally significant for cultivars $(P=0.06)$ and MSUS clones $(P=0.06)$ inoculated with C. fragariae isolate $\mathrm{Cf}-75$ but was not significant for cultivars $(P=$ $0.48)$ or MSUS clones $(P=0.24)$ inoculated with $C$. gloeosporioides isolate Cg-162 (Table 1). Since all germplasm lines were not inoculated with all isolates in each of the three seasons and the seasonal effect was not significant for all germplasm lines by season interactions, data from all seasons were combined. However, these data suggest that there is a possible seasonal effect that should be considered when using this assay.

The WP-DSR and L-DSR were found to have a very high degree of association $\left(r_{p}=0.96\right)$. The association between the L-DSR and DL-DSR $\left(r_{p}=0.70\right)$ was positive. The association between the WP-DSR and DL-DSR was also positive $\left(r_{p}=0.66\right)$, slightly less than the association between the L-DSR and DL-DSR, but moderately less than the association between the WP-DSR and L-DSR from the whole plant inoculations. This is not unexpected since detached leaf assay was rated for disease severity five DAI compared with the 30 DAI for the whole plant disease rating, thus allowing attached leaves a longer time for disease to develop.

The WP-DSR means for each of the resistance categories were found to be significantly different $(P<0.0001)$. A posthoc Tukey's test showed that the WP-DSR means of each resistance category differed significantly from each other at $P<0.05$. The categories for the WP-DSR means were then used to establish the corresponding categories for the leaf (from the same plant) L-DSR means and detached leaf (from the same plant population) DL-DSR means. The L-DSR means for each of the resistance categories were analyzed with

Table 1. Analysis of variance (ANOVA) for three seasons in which 17 cultivars and 39 MSUS clones of strawberry were inoculated with Colletotrichum fragariae isolate Cf-75 or 23 cultivars and 30 MSUS clones of strawberry were inoculated with C. gloeosporioides isolate Cg-162 for the dependent variables of whole plant disease severity rating mean and leaf disease severity rating mean. Data for each isolate were analyzed separately.

\begin{tabular}{|c|c|c|c|c|c|c|}
\hline Isolate & Germplasm group & $\mathbf{N}$ & Source of variation & df & $\frac{\text { Plant DSR }}{\mathrm{z}}$ & $\frac{\text { Leaf DSR }}{P>F}$ \\
\hline \multirow[t]{3}{*}{ Cf-75 } & Cultivar & 201 & Cultivar & 16 & $<0.0001$ & 0.0006 \\
\hline & & & Season & 2 & $<0.0001$ & $<0.0001$ \\
\hline & & & Cultivar $\times$ season & 32 & $<0.0001$ & 0.0559 \\
\hline \multirow[t]{3}{*}{ Cf-75 } & MSUS clone & 453 & MSUS clone & 38 & 0.0012 & $<0.0001$ \\
\hline & & & Season & 2 & $<0.0001$ & $<0.0001$ \\
\hline & & & MSUS clone $\times$ season & 76 & 0.0885 & 0.0640 \\
\hline \multirow[t]{3}{*}{ Cg-162 } & Cultivar & 273 & Cultivar & 22 & $<0.0001$ & $<0.0001$ \\
\hline & & & Season & 2 & $<0.0001$ & $<0.0001$ \\
\hline & & & Cultivar $\times$ season & 44 & 0.3982 & 0.4768 \\
\hline \multirow[t]{3}{*}{$\mathrm{Cg}-162$} & MSUS clone & 347 & MSUS clone & 29 & $<0.0001$ & $<0.0001$ \\
\hline & & & Season & 2 & $<0.0001$ & $<0.0001$ \\
\hline & & & MSUS clone $\times$ season & 58 & 0.0261 & 0.2354 \\
\hline
\end{tabular}

${ }^{\mathrm{z}}$ WP-DSR of cultivars (Aiko, Earliglow, Elsanta, Honeoye, Ovation, Portola, Salinas, Sequoia, Strawberry Festival, Tangi, and Tillamook) with a mean $>5.0$ was amended to equal 5 (youngest leaf wilted) for analysis of agreement between the whole plant and leaf ratings.

Table 2. Descriptive statistics of the anthracnose disease severity ratings for whole strawberry plants inoculated with three Colletotrichum isolates (Cf-63, Cf-75, and Cg-162) and assessed for disease using a 0 to 6 disease severity rating (WP-DSR) scale. The strawberry germplasm was then categorized using the WP-DSR $\leq 2.0=$ resistant, $>2.0$ and $<4.0=$ intermediate, and $\geq 4.0=$ susceptible. The categories assigned from the WP-DSRs were used for the descriptive statistics for the corresponding whole plant leaf and detached leaf disease severity ratings.

\begin{tabular}{|c|c|c|c|c|c|c|c|c|c|}
\hline Tissue & Category & $\mathbf{N}^{\mathbf{x}}$ & Mean ${ }^{y}$ & SD & Median & Min & Max & Lower $95 \%$ Mean $C^{z}$ & Upper $95 \%$ Mean CL \\
\hline \multirow[t]{3}{*}{ Whole plant (WP-DSR) } & Resistant & 87 & $1.3 \mathrm{c}$ & 0.5 & 1.3 & 0.4 & 2.0 & 1.2 & 1.4 \\
\hline & Intermediate & 90 & $2.9 \mathrm{~b}$ & 0.6 & 2.8 & 2.0 & 4.0 & 2.8 & 3.0 \\
\hline & Susceptible & 57 & $4.8 \mathrm{a}$ & 0.4 & 4.9 & 4.0 & 5.4 & 4.7 & 4.9 \\
\hline \multirow[t]{3}{*}{ Whole plant leaf (L-DSR) } & Resistant & 87 & $1.2 \mathrm{c}$ & 0.7 & 1.0 & 0.2 & 3.1 & 1.1 & 1.4 \\
\hline & Intermediate & 90 & $2.9 \mathrm{~b}$ & 0.6 & 2.8 & 1.4 & 4.2 & 2.8 & 3.0 \\
\hline & Susceptible & 57 & $4.5 \mathrm{a}$ & 0.4 & 4.6 & 3.5 & 5.0 & 4.4 & 4.6 \\
\hline \multirow[t]{3}{*}{ Detached leaf (DL-DSR) } & Resistant & 87 & $0.7 \mathrm{c}$ & 0.4 & 0.7 & 0.1 & 2.5 & 0.7 & 0.8 \\
\hline & Intermediate & 90 & $1.1 \mathrm{~b}$ & 0.6 & 1.1 & 0.2 & 2.6 & 1.0 & 1.3 \\
\hline & Susceptible & 57 & $1.9 \mathrm{a}$ & 0.6 & 2.0 & 0.7 & 3.3 & 1.7 & 2.1 \\
\hline
\end{tabular}

${ }^{\mathrm{x}} \mathrm{N}$ is the total germplasm in the designated category. The total inoculated whole plants $=2,195$, and detached leaves $=2,983$. The WP-DSR for all plants in each germplasm line was averaged across all inoculation isolates, and the average was used to assign resistance categories $(\mathrm{R}=$ resistant, $\mathrm{I}=$ intermediate, $\mathrm{S}=$ susceptible) to each germplasm line. The germplasm line mean was used in the statistical analysis.

${ }^{y}$ Means for each tissue type followed by different letters within a column are significantly different according to Tukey's test $(P<0.05)$.

${ }^{\mathrm{z}}$ Confidence limit. 
ANOVA and found to be significantly different $(P<0.0001)$. A posthoc Tukey's test showed that the L-DSR means differed significantly from each other at $P<0.05$. The DL-DSR means for each of the resistance categories were also analyzed with ANOVA and found to be significantly different $(P<0.0001)$. A posthoc Tukey's test showed that DL-DSR means differed significantly from each other at $P<$ 0.05 (Table 2).

The mean WP-DSR $(\mathrm{R}=1.3, \mathrm{I}=2.9, \mathrm{~S}=4.8)$ and mean L-DSR $(\mathrm{R}=1.2, \mathrm{I}=2.9, \mathrm{~S}=4.5)$ corresponding to the same categories were equal for the intermediate category and within 0.1 and 0.3 for the resistant and susceptible categories, respectively (Table 2). The WPDSR means for each category $(\mathrm{R}=1.3, \mathrm{I}=2.9, \mathrm{~S}=4.8)$ and the DL-DSR mean for each category $(\mathrm{R}=0.7, \mathrm{I}=1.1, \mathrm{~S}=1.9)$ were found not to be as closely related as the L-DSR means with the WP-DSR means, both of which were from the same plant. The DL-DSR category means and lower and upper $95 \%$ confidence limits (Table 2) were used to establish resistance categories (DL-DSR $\leq 0.8=$ resistant; DL-DSR $>0.8$ and $\leq 1.6=$ intermediate, and DLDSR $>1.6=$ susceptible.

Germplasm lines were classified into resistance categories based on the WP-DSRs for each germplasm line for each isolate across seasons using WP-DSR $\leq 2.0=$ resistant, WP-DSR $>2.0$ or $<4.0=$ intermediate, and WP-DSR $\geq 4.0=$ susceptible (Table 3 ). Among the standard cultivars used for disease comparison, 'Elsanta' was intermediate to $C$. fragariae isolate Cf-63 and susceptible to $C$. fragariae isolate $\mathrm{Cf}-75$ and C. gloeosporioides isolate Cg-162; 'Chandler' was susceptible to both C. fragariae isolates and C. gloeosporioides isolate Cg-162; and 'Pelican' was resistant to $C$. fragariae isolate $\mathrm{Cf}-63$ and $C$. gloeosporioides isolate $\mathrm{Cg}-162$ and intermediate to $C$. fragariae isolate $\mathrm{Cf}-75$.

Based on the WP-DSRs, more cultivars were resistant to $C$. acutatum isolate Goff (14 of 31) than to Ca-1 (5 of 30), but more MSUS clones were resistant to Ca-1 (43 of 44) than to Goff (34 of 42) (Table 3). C. fragariae isolate Cf-63 was less aggressive than Cf75 with 4 of 29 (14\%) cultivars and 40 of 42 (95\%) MSUS clones

Table 3. Anthracnose resistance category ${ }^{\mathrm{v}}$ based on average disease severity rating (DSR) for whole plant (WP-DSR ${ }^{\mathrm{w}}$ ), leaf (L-DSR ${ }^{\mathrm{x}}$ ), and detached leaf (DL-DSR ${ }^{y}$ ) of strawberry germplasm inoculated with isolates of three Colletotrichum species. (Italicized cells indicate a difference in category between WP-DSR and DL-DSR, and cells in bold indicate a difference in category between WP-DSR and L-DSR.)

\begin{tabular}{|c|c|c|c|c|c|c|c|c|c|}
\hline \multirow[b]{3}{*}{ Germplasm } & \multicolumn{2}{|c|}{ C. acutatum } & \multicolumn{4}{|c|}{ C. fragariae } & \multicolumn{3}{|c|}{ C. gloeosporioides } \\
\hline & CA-1 & Goff & CF-63 ${ }^{z}$ & CF-75 & CF-75 & CF-75 & CG-162 & CG-162 & CG-162 \\
\hline & WP-DSR & $\overline{\text { WP-DSR }}$ & WP-DSR & $\overline{\text { WP-DSR }}$ & L-DSR & $\overline{\text { DL-DSR }}$ & $\overline{\text { WP-DSR }}$ & L-DSR & DL-DSR \\
\hline \multicolumn{10}{|l|}{ Cultivars } \\
\hline Aiko & $\mathrm{S}$ & I & I & $\mathrm{S}$ & $\mathrm{S}$ & $\mathrm{S}$ & $\mathrm{S}$ & $\mathrm{S}$ & $\mathrm{S}$ \\
\hline Albion & I & I & I & S & $S$ & S & $\mathrm{S}$ & S & $\mathrm{S}$ \\
\hline Allstar & I & I & I & I & I & $S$ & $\mathrm{~S}$ & I & $I$ \\
\hline Aromas & I & I & I & S & $S$ & S & $\mathrm{S}$ & $S$ & S \\
\hline Camino Real & $\mathrm{R}$ & $\mathrm{R}$ & $\mathrm{S}$ & $\mathrm{S}$ & $\mathrm{S}$ & $\mathrm{S}$ & $\mathrm{S}$ & $\mathrm{S}$ & $\mathrm{S}$ \\
\hline Chandler & I & I & $\mathrm{S}$ & $\mathrm{S}$ & I & $\mathrm{S}$ & $\mathrm{S}$ & $\mathrm{S}$ & $\mathrm{S}$ \\
\hline Diamante & I & I & I & $S$ & $S$ & S & $S$ & $S$ & $I$ \\
\hline Dover & - & $\mathrm{R}$ & $\mathrm{R}$ & I & I & I & I & $\mathbf{S}$ & $S$ \\
\hline Earliglow & I & $\mathrm{R}$ & I & $\mathrm{S}$ & $\mathrm{S}$ & $\mathrm{S}$ & $\mathrm{S}$ & $\mathrm{S}$ & $I$ \\
\hline Elsanta & $\mathrm{S}$ & $\mathrm{S}$ & I & $\mathrm{S}$ & $\mathrm{S}$ & $\mathrm{S}$ & $\mathrm{S}$ & $\mathrm{S}$ & $\mathrm{S}$ \\
\hline Gaviota & $\mathrm{S}$ & I & $\mathrm{S}$ & $\mathrm{S}$ & $\mathrm{S}$ & $\mathrm{S}$ & $\mathrm{S}$ & $\mathrm{S}$ & $\mathrm{S}$ \\
\hline Honeoye & I & $\mathrm{R}$ & I & $S$ & S & S & $\mathrm{S}$ & S & S \\
\hline Jewel & I & $\mathrm{I}$ & $S$ & $\mathrm{~S}$ & S & S & $\mathrm{S}$ & S & S \\
\hline Kent & I & I & S & $\mathrm{I}$ & $\mathbf{S}$ & $S$ & $\mathrm{~S}$ & S & $I$ \\
\hline Ovation & $\mathrm{R}$ & $\mathrm{R}$ & I & $\mathrm{S}$ & S & $I$ & S & S & S \\
\hline Pelican & $\mathrm{R}$ & $\mathrm{R}$ & $\mathrm{R}$ & I & I & $R$ & $\mathrm{R}$ & $\mathrm{R}$ & $\mathrm{R}$ \\
\hline Portola & $\mathrm{S}$ & I & I & $\mathrm{S}$ & $\mathrm{S}$ & $\mathrm{S}$ & $\mathrm{S}$ & $\mathrm{S}$ & $\mathrm{S}$ \\
\hline Redchief & I & I & $\mathrm{S}$ & $\mathrm{S}$ & I & $\mathrm{S}$ & $\mathrm{S}$ & $\mathrm{S}$ & $R$ \\
\hline Salinas & I & I & I & S & S & S & S & $\mathrm{S}$ & S \\
\hline Scott & $\mathrm{S}$ & $\mathrm{R}$ & S & S & S & S & S & $\mathrm{S}$ & S \\
\hline Seascape & $\mathrm{R}$ & $\mathrm{R}$ & I & S & S & S & S & S & $I$ \\
\hline Selva & I & I & $\mathrm{S}$ & $\mathrm{S}$ & $\mathrm{S}$ & $\mathrm{S}$ & $\mathrm{S}$ & $\mathrm{S}$ & $I$ \\
\hline Senga Sengana & S & $\mathrm{R}$ & $\mathrm{R}$ & I & I & I & $\mathrm{S}$ & S & S \\
\hline Sequoia & I & $\mathrm{R}$ & I & I & I & $S$ & $\mathrm{~S}$ & S & $I$ \\
\hline Straw Festival & S & $\mathrm{R}$ & S & S & S & $\mathrm{S}$ & $\mathrm{S}$ & $\mathrm{S}$ & S \\
\hline Surecrop & I & I & - & S & S & $\mathrm{S}$ & S & S & $I$ \\
\hline Sweet Charlie & I & $\mathrm{R}$ & I & I & I & $S$ & S & S & S \\
\hline Tangi & I & $\mathrm{R}$ & I & S & S & S & I & I & I \\
\hline Tillamook & $\mathrm{S}$ & I & - & $\mathrm{S}$ & $\mathrm{S}$ & $\mathrm{S}$ & $\mathrm{S}$ & $\mathrm{S}$ & $I$ \\
\hline Tioga & $\mathrm{R}$ & $\mathrm{R}$ & $\mathrm{R}$ & I & I & $S$ & $\mathrm{~S}$ & $\mathrm{~S}$ & $\mathrm{~S}$ \\
\hline Treasure & $\mathrm{S}$ & I & I & I & I & $S$ & I & $\mathbf{S}$ & $S$ \\
\hline Total clones & 30 & 31 & 29 & 31 & 31 & 31 & 31 & 31 & 31 \\
\hline Resistant (no.) & 5 & 14 & 4 & 0 & 0 & 1 & 1 & 1 & 2 \\
\hline Resistant (\%) & 16.7 & 45.2 & 13.8 & 0.0 & 0.0 & 3.2 & 3.2 & 3.2 & 6.5 \\
\hline \multirow[t]{2}{*}{ Average DSR } & 3.23 & 2.28 & 3.58 & 4.31 & 4.25 & 2.06 & 4.69 & 4.46 & 1.63 \\
\hline & & & & & & & & \multicolumn{2}{|c|}{ (Continued on next page) } \\
\hline
\end{tabular}

${ }^{\mathrm{v}}$ Anthracnose resistance categories: $\mathrm{R}=$ resistant, $\mathrm{I}=$ intermediate, $\mathrm{S}=$ susceptible.

w WP-DSR scale: $0=$ healthy plant with no visible lesions, $1=\leq 3 \mathrm{~mm}$ long petiole lesion, $2=3-10 \mathrm{~mm}$ long petiole lesion, $3=>10-20 \mathrm{~mm}$ long petiole lesion, $4=>20 \mathrm{~mm}$ long petiole lesion, $5=$ youngest leaf wilted, and $6=$ plant dead; WP-DSR $<2.0=\mathrm{R},>2.0$ and $<4.0=\mathrm{I}$, and $>4.0=\mathrm{S}$.

${ }^{x}$ L-DSR scale: $0=$ no visible lesions, 1 through $4=$ increasing disease symptom severity, and $5=$ total area of leaflets necrotic; $\mathrm{L}-\mathrm{DSR}<2.0=\mathrm{R},>2.0$ and $<4.0=\mathrm{I}$, and $>4.0=\mathrm{S}$.

${ }^{\mathrm{y}}$ DL-DSR scale: $0=$ no visible lesions, 1 through $4=$ increasing disease symptom severity, and $5=$ total area of leaflets necrotic; DL-DSR $\leq 0.8=\mathrm{R},>0.8$ and $\leq 1.6=\mathrm{I}$, and $>1.6=\mathrm{S}$.

${ }^{\mathrm{z}}$ C. fragariae isolate Cf-63 L-DSR and DL-DSR were removed from the table because less than 12 detached leaves were inoculated per germplasm line. 
categorized resistant. Among germplasm lines inoculated with C. fragariae isolate Cf-75, no cultivars and 18 of 44 (41\%) MSUS clones were resistant; and among lines inoculated with $C$. gloeosporioides isolate Cg-162, only 'Pelican' of 31 cultivars and 16 of 44 (36\%) MSUS clones were resistant.

Among the detached leaves inoculated with $C$. fragariae isolate Cf-75, only 'Pelican' of 31 cultivars and 12 of 44 (27\%) MSUS clones were resistant. Among the detached leaves inoculated with C. gloeosporioides isolate Cg-162, two ('Pelican' and 'Redchief') of 31 cultivars and 28 of $44(64 \%)$ MSUS clones were resistant. The Cochran-Mantel-Haenszel statistic used to test the null hypothesis of no association among the categories (resistant, intermediate, or susceptible) and WP-DSRs, indicated the probability of no association was significant $(P<0.0001)$. Some differences in the resistance category were found between the WP-DSR and the DL-DSR. Eight cultivars and 21 MSUS clones inoculated with Cf-75 and 12 cultivars and 21 MSUS clones inoculated with $\mathrm{Cg}-162$ did not match exactly (indicated by italic font in Table 3 ).

Seventy-five germplasm lines were inoculated with $C$. fragariae isolate Cf-75. Eighteen were classified as resistant in the whole plant assay, and 13 were classified as resistant in the detached leaf assay. The same 75 germplasm lines were inoculated with $C$. gloeosporioides isolate Cg-162, and 17 were classified as resistant in the whole plant assay and 30 were classified as resistant in the detached leaf assay.

\section{Discussion}

Developing and releasing a new strawberry cultivar generally takes many years. Any time reduction during the process is a plus

Table 3. (Continued from previous page)

\begin{tabular}{|c|c|c|c|c|c|c|c|c|c|}
\hline \multirow[b]{3}{*}{ Germplasm } & \multicolumn{2}{|c|}{ C. acutatum } & \multicolumn{4}{|c|}{ C. fragariae } & \multicolumn{3}{|c|}{ C. gloeosporioides } \\
\hline & CA-1 & Goff & CF-63z & CF-75 & CF-75 & CF-75 & CG-162 & CG-162 & CG-162 \\
\hline & WP-DSR & WP-DSR & WP-DSR & WP-DSR & L-DSR & DL-DSR & WP-DSR & L-DSR & DL-DSR \\
\hline \multicolumn{10}{|c|}{ US \& MSUS clones } \\
\hline US 70 & $\mathrm{R}$ & $\mathrm{R}$ & - & I & $\mathbf{R}$ & $R$ & $\mathrm{R}$ & $\mathrm{R}$ & $\mathrm{R}$ \\
\hline US 159 & $\mathrm{R}$ & $\mathrm{I}$ & $\mathrm{R}$ & I & $\mathrm{I}$ & I & I & I & I \\
\hline US 292 & $\mathrm{R}$ & $\mathrm{R}$ & $\mathrm{I}$ & I & I & $\mathrm{I}$ & I & I & $R$ \\
\hline MSUS 478 & $\mathrm{R}$ & $\mathrm{I}$ & $\mathrm{R}$ & I & I & $\mathrm{I}$ & I & I & $\mathrm{I}$ \\
\hline MSUS 518 & $\mathrm{R}$ & $\mathrm{R}$ & $\mathrm{R}$ & I & I & $\mathrm{I}$ & I & I & $R$ \\
\hline MSUS 572 & $\mathrm{R}$ & $\mathrm{R}$ & $\mathrm{R}$ & I & I & $S$ & I & I & $S$ \\
\hline MSUS 574 & $\mathrm{R}$ & $\mathrm{R}$ & $\mathrm{R}$ & $\mathrm{R}$ & I & $I$ & I & I & I \\
\hline MSUS 868 & $\mathrm{R}$ & $\mathrm{R}$ & $\mathrm{R}$ & $\mathrm{R}$ & $\mathrm{R}$ & $\mathrm{R}$ & $\mathrm{R}$ & $\mathrm{R}$ & $\mathrm{R}$ \\
\hline MSUS 912 & $\mathrm{R}$ & I & $\mathrm{R}$ & $\mathrm{R}$ & $\mathrm{R}$ & $I$ & $\mathrm{R}$ & $\mathrm{R}$ & $\mathrm{R}$ \\
\hline MSUS 922 & $\mathrm{R}$ & $\mathrm{R}$ & $\mathrm{R}$ & $\mathrm{R}$ & $\mathrm{R}$ & $I$ & $\mathrm{R}$ & $\mathrm{R}$ & $S$ \\
\hline MSUS 927 & $\mathrm{R}$ & $\mathrm{R}$ & $\mathrm{R}$ & I & I & $\mathrm{I}$ & I & I & $R$ \\
\hline MSUS 933 & $\mathrm{R}$ & $\mathrm{R}$ & $\mathrm{R}$ & I & I & $S$ & I & $\mathbf{S}$ & I \\
\hline MSUS 944 & $\mathrm{R}$ & $\mathrm{R}$ & $\mathrm{R}$ & I & I & $R$ & I & I & $R$ \\
\hline MSUS 1010 & $\mathrm{R}$ & $\mathrm{R}$ & $\mathrm{R}$ & $\mathrm{R}$ & $\mathrm{R}$ & $\mathrm{R}$ & I & I & $R$ \\
\hline MSUS 1039 & $\mathrm{R}$ & I & $\mathrm{R}$ & I & I & I & I & I & $R$ \\
\hline MSUS 1049 & $\mathrm{R}$ & $\mathrm{R}$ & $\mathrm{R}$ & $\mathrm{R}$ & I & $I$ & $\mathrm{R}$ & $\mathrm{R}$ & $S$ \\
\hline MSUS 1055 & $\mathrm{R}$ & $\mathrm{R}$ & $\mathrm{R}$ & I & I & $R$ & $\mathrm{R}$ & $\mathrm{R}$ & $\mathrm{R}$ \\
\hline MSUS 1061 & $\mathrm{R}$ & I & $\mathrm{R}$ & $\mathrm{R}$ & $\mathrm{R}$ & $I$ & $\mathrm{R}$ & $\mathrm{R}$ & $\mathrm{R}$ \\
\hline MSUS 1066 & $\mathrm{R}$ & $\mathrm{R}$ & $\mathrm{R}$ & $\mathrm{R}$ & $\mathrm{R}$ & $I$ & I & I & $R$ \\
\hline MSUS 1078 & $\mathrm{R}$ & $\mathrm{R}$ & $\mathrm{R}$ & $\mathrm{R}$ & $\mathrm{R}$ & $I$ & I & I & I \\
\hline MSUS 1093 & $\mathrm{R}$ & $\mathrm{R}$ & $\mathrm{R}$ & $\mathrm{R}$ & $\mathrm{R}$ & $\mathrm{R}$ & I & I & $R$ \\
\hline MSUS 1094 & I & I & $\mathrm{R}$ & $\mathrm{R}$ & I & $I$ & $\mathrm{R}$ & $\mathrm{R}$ & $\mathrm{R}$ \\
\hline MSUS 1142 & $\mathrm{R}$ & $\mathrm{R}$ & $\mathrm{R}$ & I & I & I & I & I & I \\
\hline MSUS 1154 & $\mathrm{R}$ & $\mathrm{R}$ & $\mathrm{R}$ & $\mathrm{R}$ & I & $\mathrm{R}$ & $\mathrm{R}$ & $\mathrm{R}$ & $\mathrm{R}$ \\
\hline MSUS 1180 & $\mathrm{R}$ & $\mathrm{R}$ & $\mathrm{R}$ & I & $\mathbf{R}$ & $R$ & I & I & $R$ \\
\hline MSUS 1196 & $\mathrm{R}$ & $\mathrm{R}$ & $\mathrm{R}$ & I & I & I & I & I & I \\
\hline MSUS 1197 & $\mathrm{R}$ & $\mathrm{R}$ & $\mathrm{R}$ & I & I & $S$ & I & I & $R$ \\
\hline MSUS 1217 & $\mathrm{R}$ & $\mathrm{R}$ & $\mathrm{R}$ & I & I & $S$ & I & I & $R$ \\
\hline MSUS 1229 & $\mathrm{R}$ & $\mathrm{R}$ & $\mathrm{R}$ & I & I & I & I & I & $R$ \\
\hline MSUS 1230 & $\mathrm{R}$ & - & I & I & I & I & I & I & I \\
\hline MSUS 1240 & $\mathrm{R}$ & $\mathrm{R}$ & $\mathrm{R}$ & $\mathrm{R}$ & I & $S$ & I & $\mathrm{I}$ & I \\
\hline MSUS 1265 & $\mathrm{R}$ & - & $\mathrm{R}$ & $\mathrm{R}$ & $\mathrm{R}$ & $I$ & $\mathrm{R}$ & $\mathrm{R}$ & $\mathrm{R}$ \\
\hline MSUS 1269 & $\mathrm{R}$ & $\mathrm{R}$ & $\mathrm{R}$ & I & I & $R$ & I & I & I \\
\hline MSUS 1270 & $\mathrm{R}$ & $\mathrm{R}$ & $\mathrm{R}$ & I & I & I & I & I & $R$ \\
\hline MSUS 1271 & $\mathrm{R}$ & I & $\mathrm{R}$ & I & I & I & I & I & $R$ \\
\hline MSUS 1311 & $\mathrm{R}$ & $\mathrm{R}$ & $\mathrm{R}$ & $\mathrm{R}$ & $\mathrm{R}$ & $\mathrm{R}$ & $\mathrm{R}$ & $\mathrm{R}$ & $I$ \\
\hline MSUS 1343 & $\mathrm{R}$ & $\mathrm{R}$ & $\mathrm{R}$ & $\mathrm{R}$ & I & $\mathrm{R}$ & I & I & $R$ \\
\hline MSUS 1352 & $\mathrm{R}$ & $\mathrm{R}$ & $\mathrm{R}$ & I & I & I & I & I & $R$ \\
\hline MSUS 1356 & $\mathrm{R}$ & $\mathrm{R}$ & $\mathrm{R}$ & I & I & I & $\mathrm{R}$ & $\mathrm{R}$ & $\mathrm{R}$ \\
\hline MSUS 1359 & $\mathrm{R}$ & $\mathrm{R}$ & $\mathrm{R}$ & $\mathrm{R}$ & $\mathrm{R}$ & $I$ & $\mathrm{R}$ & $\mathrm{R}$ & $\mathrm{R}$ \\
\hline MSUS 1362 & $\mathrm{R}$ & $\mathrm{R}$ & $\mathrm{R}$ & $\mathrm{R}$ & $\mathrm{R}$ & $\mathrm{R}$ & $\mathrm{R}$ & $\mathrm{R}$ & $\mathrm{R}$ \\
\hline MSUS 1365 & $\mathrm{R}$ & I & $\mathrm{R}$ & I & $\mathbf{R}$ & $S$ & $\mathrm{R}$ & $\mathrm{R}$ & $I$ \\
\hline MSUS 1426 & $\mathrm{R}$ & $\mathrm{R}$ & - & I & I & I & $\mathrm{R}$ & $\mathrm{R}$ & $\mathrm{R}$ \\
\hline MSUS 1511 & $\mathrm{R}$ & $\mathrm{R}$ & $\mathrm{R}$ & I & I & I & I & I & I \\
\hline Total clones & 44 & 42 & 42 & 44 & 44 & 44 & 44 & 44 & 44 \\
\hline Resistant (no.) & 43 & 34 & 40 & 18 & 15 & 12 & 16 & 16 & 28 \\
\hline Resistant (\%) & 97.7 & 81.0 & 95.2 & 40.9 & 34.1 & 27.3 & 36.4 & 36.4 & 63.6 \\
\hline Average DSR & 0.97 & 1.32 & 1.08 & 2.15 & 2.32 & 1.12 & 2.33 & 2.33 & 0.83 \\
\hline
\end{tabular}


for the breeder and grower and, ultimately, for the public who benefits by the availability of strawberry fruit. Strawberry germplasm must be clonally propagated to facilitate screening research, whether screening for disease resistance or horticultural traits. This adds a considerable amount of time to the overall process of cultivar development. Screening germplasm for disease resistance may require years of greenhouse and field testing. Inoculating detached strawberry leaves with anthracnose pathogens allows assessment for anthracnose resistance without destroying whole plants and lessens the time between inoculation and disease assessment. The detached leaf assay provides a rapid, nondestructive method of reliably identifying anthracnose-resistant germplasm, thus allowing the screening process to move forward with enhanced efficiency. Inoculation studies performed in a laboratory permit the environment (temperature, humidity, and light) to be controlled more consistently than in a greenhouse, confines the pathogen to the laboratory, and requires less space.

Our research supports previous research using disease severity ratings obtained from whole plant inoculations to separate strawberry germplasm into three resistance categories: resistant, intermediate, and susceptible (Lewers et al. 2007; Smith and Black 1987, 1990). The category means for the WP-DSR and L-DSR were almost equivalent, as would have been expected, but had not been reported prior to this research. This demonstrates that the whole plant disease severity rating corresponds well to the leaf tissue disease severity rating obtained from the same plant. The overall means for each resistance category based on the WP-DSR, L-DSR, and DL-DSR were found to be significantly different based on Tukey's test. There were greater differences between each category mean of the WP-DSR and DL-DSR than between each category mean of the WP-DSR and L-DSR; however, the much lower category mean of the DL-DSR was to be expected because the detached leaves did not have as long to develop symptoms as leaves on the whole plants. The mean DLDSRs for each resistance category were found to be significantly different from each other, based on Tukey's test, and adds credibility to using a detached leaf assay for separating resistant germplasm from susceptible germplasm in preliminary screening.

C. acutatum may cause anthracnose symptoms on the roots, crown, and aboveground parts of the strawberry plant (Howard et al. 1992; Smith 1998c), but it primarily causes a severe fruit rot. While developing a detached leaf assay, we found that 5 days was not sufficient to allow $C$. acutatum symptoms to develop on strawberry leaves, which supports the findings of Curry et al. (2002) that $C$. acutatum and $C$. fragariae have similar infection processes, but C. acutatum invaded the strawberry tissue more slowly than $\operatorname{did} C$. fragariae. Cultivars identified as resistant to the $C$. acutatum isolates in the whole plant inoculations were identified as either intermediate or susceptible to the $C$. fragariae or $C$. gloeosporioides isolates in the detached leaf inoculations, except for 'Redchief.' Based on the whole plant assay, 'Redchief' was intermediate to the $C$. acutatum isolates and susceptible to the $C$. fragariae and C. gloeosporioides isolates; however, it was found resistant to $C$. gloeosporioides in the detached leaf assay. Since $C$. acutatum primarily causes a fruit rot rather than petiole lesions or leaf spots, this is not surprising. Further research is needed to determine if there is a correlation between the susceptibility of a germplasm line to fruit rot caused by C. acutatum and the susceptibility of its leaves to C. fragariae or C. gloeosporioides in either the whole plant or detached leaf assays.

Preliminary research indicated that anthracnose-resistant germplasm could be distinguished from susceptible germplasm using inoculated detached strawberry leaves and that a 0 to 5 ordinal scale was sufficient for rating the disease severity (Miller-Butler et al. 2013). Our current research compared the disease severity ratings following inoculation of whole plants (benchmark), a single leaf from each of the whole plants, and detached leaves, and found that all three assays were able to distinguish significant differences among the resistance categories (Table 2). Although the correlation between the whole plant and detached leaf assays was 0.7 , this research indicated that the strawberry detached leaf assay is reliable and can be used to quickly determine the resistance or susceptibility of strawberry germplasm to anthracnose. The detached leaf assay has also been used to evaluate natural products as potential fungicides (Abril et al. 2009).

\section{Literature Cited}

Abe, K., Iwanami, H., Kotoda, N., Moriya, S., and Takahashi (Sumiyoshi), S. 2010. Evaluation of apple genotypes and Malus species for resistance to Alternaria blotch caused by Alternaria alternata apple pathotype using detached-leaf method. Plant Breed. 129:208-218.

Abril, M., Curry, K. J., Smith, B. J., Delucca, A. J., Boue, S., and Wedge, D. E. 2009. Greenhouse and field evaluation of the natural saponin Cay-1 for control of several strawberry diseases. Int. J. Fruit Sci. 9:211-220.

Agrios, G. N. 2005. Plant Pathology, 5th ed. Elsevier Academic Press, Burlington, MA.

Altschul, S. F., Madden, T. L., Schäffer, A. A., Zhang, J., Zhang, Z., Miller, W., and Lipman, D. J. 1997. Gapped BLAST and PSI-BLAST: A new generation of protein database search programs. Nucleic Acids Res. 25:3389-3402.

Babiker, E. M., Hulbert, S. H., and Paulitz, T. C. 2012. Hyaloperonospora camelinae on Camelina sativa in Washington State: Detection, seed transmission, and chemical control. Plant Dis. 96:1670-1674.

Chang, P., and Smith, B. J. 2007. Response of 'Treasure' and 22 Florida strawberry genotypes to the anthracnose pathogens Colletotrichum acutatum, C. fragariae, and C. gloeosporioides. Pages 69-73 in: Proceedings of 2007 North American Strawberry Symposium. F. Takeda, D. T. Handley, and E. B. Poling, eds. North American Strawberry Growers Association, Kemptville, ON, Canada.

Curry, K. J., Abril, M., Avant, J. B., and Smith, B. J. 2002. Strawberry anthracnose: Histopathology of Colletotrichum acutatum and C. fragariae. Phytopathology 92:1055-1063.

Damm, U., Cannon, P. F., Woudenberg, J. H. C., and Crous, P. W. 2012. The Colletotrichum acutatum species complex. Stud. Mycol. 73:37-113.

Delp, B. R., and Milholland, R. D. 1980. Evaluating strawberry plants for resistance to Colletotrichum fragariae. Plant Dis. 64:1071-1073.

Delp, B. R., and Milholland, R. D. 1981. Susceptibility of strawberry cultivars and related species to Colletotrichum fragariae. Plant Dis. 65:421-423.

Denoyes, B., and Baudry, A. 1995. Species identification and pathogenicity study of French Colletotrichum strains isolated from strawberry using morphological and cultural characteristics. Phytopathology 85:53-57.

Denoyes-Rothan, B., and Guérin, G. 1996. Comparison of six inoculation techniques with Colletotrichum acutatum on cold stored strawberry plants and screening for resistance to this fungus in French strawberry collections. Eur. J. Plant Pathol. 102:615-621.

Foolad, M. R., Sullenberger, M. T., and Ashrafi, H. 2015. Detached-leaflet evaluation of tomato germplasm for late blight resistance and its correspondence to field and greenhouse screenings. Plant Dis. 99:718-722.

Forcelini, B. B., Seijo, T. E., Amiri, A., and Peres, N. A. 2016. Resistance in strawberry isolates of Colletotrichum acutatum from Florida to quinone outside inhibitor fungicides. Plant Dis. 100:2050-2056.

Galletta, G. J., Smith, B. J., and Gupton, C. L. 1993. Strawberry parent clones US 70, US 159, US 292, and US 438 resistant to anthracnose crown rot. HortScience 28:1055-1056.

Gwet, K. L. 2012. Handbook of Inter-rater Reliability: The Definitive Guide to Measuring the Extent of Agreement Among Raters. Advanced Analytics, Gaithersburg, MD.

Howard, C. M., Maas, J. L., Chandler, C. K., and Albregts, E. E. 1992 Anthracnose of strawberry caused by the Colletotrichum complex in Florida. Plant Dis. 76:976-981.

Lewers, K. S., Turechek, W. W., Hokanson, S. C., Maas, J. L., Hancock, J. F., Serce, S., and Smith, B. J. 2007. Evaluation of elite native strawberry germplasm for resistance to anthracnose crown rot disease caused by Colletotrichum species. J. Am. Soc. Hortic. Sci. 132:842-849.

Miller-Butler, M. A., Curry, K. J., Kreiser, B. R., and Smith, B. J. 2013. Visual and electronic evaluations of detached strawberry leaves inoculated with Colletotrichum species. Int. J. Fruit Sci. 13:114-125.

Munir, M., Amsden, B., Dixon, E., Vaillancourt, L., and Gauthier, N. W. 2016. Characterization of Colletotrichum species causing bitter rot of apple in Kentucky orchards. Plant Dis. 100:2194-2203.

Newhouse, A. E., Spitzer, J. E., Maynard, C. A., and Powell, W. A. 2014. Chestnut leaf inoculation assay as a rapid predictor of blight susceptibility. Plant Dis. 98 4-9.

O'Donnell, K., and Cigelnik, E. 1997. Two divergent intragenomic rDNA ITS2 types within a monophyletic lineage of the fungus Fusarium are nonorthologous. Mol. Phylogenet. Evol. 7:103-116.

Osorio, L. F., Pattison, J. A., Peres, N. A., and Whitaker, V. M. 2014. Genetic variation and gains in resistance of strawberry to Colletotrichum gloeosporioides. Phytopathology 104:67-74.

Poling, E. B. 2008. Anthracnose on strawberry: Its etiology, epidemiology, and pathology, together with management strategies for strawberry nurseries: Introduction to the workshop. HortScience 43:59-65.

Rahman, M., and Louws, F. J. 2008. Colletotrichum gloeosporioides on strawberry: From nursery to fruiting field. Page 54 in: Colletotrichum Diseases of Fruit Crops. N. A. Peres and L. W. Timmer, eds. Pre-Congress workshop, ICPP 2008, August 24, Torino, Italy. 
Simmonds, J. H. 1965. A study of the species Colletotrichum causing ripe fruit rots in Queensland. Queensl. J. Agric. Anim. Sci. 22:437-459.

Smith, B. J. 1998a. Anthracnose Crown Rot. Pages 46-48 in: Compendium of Strawberry Disease, 2nd Ed., J. L. Mass, ed. American Phytopathological Society, St. Paul, MN.

Smith, B. J. 1998b. Anthracnose Fruit Rot (Black Spot). Pages 31-33 in: Compendium of Strawberry Disease, 2nd Ed., J. L. Mass, ed. American Phytopathological Society, St. Paul, MN.

Smith, B. J. 1998c. Anthracnose leaf spot and irregular leaf spot. Pages 24-25 in: Compendium of Strawberry Disease, 2nd Ed., J. L. Mass, ed. American Phytopathological Society, St. Paul, MN.

Smith, B. J. 2006. USDA-ARS Strawberry anthracnose resistance breeding program. Acta Hortic.: 463-470.

Smith, B. J. 2008. Epidemiology and pathology of strawberry anthracnose: A North American perspective. HortScience 43:69-73.

Smith, B. J., and Black, L. L. 1986. First report of Colletotrichum acutatum on strawberry in the United States. Plant Dis. 70:1074.

Smith, B. J., and Black, L. L. 1987. Resistance of strawberry plants to Colletotrichum fragariae affected by environmental conditions. Plant Dis. 71:834-837.

Smith, B. J., and Black, L. L. 1990. Morphological, cultural, and pathogenic variation among Colletotrichum species isolated from strawberry. Plant Dis. 74:69-76.
Smith, B. J., Gupton, C. L., Galletta, G. J., Maas, J. L., Enns, J. M., Ballington, J. R., Jr., Constantin, R. J., DiVittorio, T. J., and Himelrick, D. 1998. 'Pelican' Strawberry. HortScience 33:1082-1084.

Smith, B. J., and Spiers, J. M. 1982. Evaluating techniques for screening strawberry seedlings for resistance to Colletotrichum fragariae. Plant Dis. 66 559-561.

Smith, B. J., Wedge, D. E., and Pace, P. F. 2013. A microtiter assay shows effectiveness of fungicides for control of Colletotrichum spp. from strawberry. Int. J. Fruit Sci. 13:205-216.

Templeton, M. D., Rikkerink, E. H. A., Solon, S. L., and Crowhurst, R. N. 1992 Cloning and molecular characterization of the glyceraldehyde-3-phosphate dehydrogenase-encoding gene and cDNA from the plant pathogenic fungus Glomerella cingulata. Gene 122:225-230.

Viera, A. J., and Garrett, J. M. 2005. Understanding interobserver agreement: The kappa statistic. Fam. Med. 37:360-363.

Weir, B. S., Johnston, P. R., and Damm, U. 2012. The Colletotrichum gloeosporioides species complex. Stud. Mycol. 73:115-180.

White, T. J., Bruns, T., Lee, S., and Taylor, J. 1990. Amplification and direct sequencing of fungal ribosomal RNA genes for phylogenetics. Pages 315-322 in: PCR Protocols: A Guide to Methods and Applications. M. A. Innis, D. H. Gelfand, J. J. Sninsky, and T. J. White, eds. Academic Press Inc., New York, NY. 